\title{
EFEITOS DOS POLUENTES ATMOSFÉRICOS E INTERNAÇÕES HOSPITALARES POR DOENÇAS CARDIOVASCULARES NO MUNICÍPIO DE TAUBATÉ- SP
}

Paola Cristina Ribeiro'

Luiz Fernando Costa Nascimento ${ }^{2}$

Resumo: Com o desenvolvimento das cidades e o aumento da população, altas taxas de poluentes são emitidos na atmosfera, ao mesmo tempo milhões de reais são gastos com internações por doenças cardiovasculares, nas grandes cidades como no estado de São Paulo. O efeito desses poluentes gera custos e danos à saúde, tendo que se estudar a sua significância nas internações por doenças do aparelho cardiovascular. Este estudo apresenta uma analise do levantamento dos dados dos poluentes atmosféricos, como o gás carbônico (CO2), monóxido de carbono (CO), dióxido de enxofre (SO2), óxidos de nitrogênio (NOx), material particulado (MP), disponibilizados pelo programa CCATT-BRAMS do CEPTEC-INPE, e as internações hospitalares no município de Taubaté-SP, no período de agosto de 2011 a julho de 2012.

Palavras-chave: Aparelho cardiovascular; Poluição; Internações; Estudo ecológico.

\footnotetext{
${ }^{1}$ Programa de Pós Graduação em Ciências Ambientais/UNITAU, Brasil. País. E-mail: paola-cr@hotmail.com.

2 Programa de Pós Graduação em Ciências Ambientais/UNITAU, Brasil. País. E-mail: luiz.nascimento@pq.cnpq.br.
} 